\title{
Isolation of mesenchymal stem cells from equine umbilical cord blood
}

\author{
Thomas G Koch*1,2, Tammy Heerkens ${ }^{1}$, Preben D Thomsen ${ }^{2}$ and \\ Dean $\mathrm{H}_{\text {Betts }}{ }^{1}$
}

\begin{abstract}
Address: ${ }^{1}$ Department of Biomedical Sciences, University of Guelph, Guelph, ON, N1G 2W1, Canada and ${ }^{2}$ Department of Basic Animal and Veterinary Sciences, University of Copenhagen, Grønnegårdsvej 7,1870 Frederiksberg C, Denmark

Email: Thomas G Koch* - tkoch@uoguelph.ca; Tammy Heerkens - theerken@uoguelph.ca; Preben D Thomsen - pdt@life.ku.dk; Dean H Betts - bettsd@uoguelph.ca

* Corresponding author
\end{abstract}

Published: 30 May 2007

BMC Biotechnology 2007, 7:26 doi:10.1 186/1472-6750-7-26
Received: 29 January 2007

Accepted: 30 May 2007

This article is available from: http://www.biomedcentral.com/1472-6750/7/26

(C) 2007 Koch et al; licensee BioMed Central Ltd.

This is an Open Access article distributed under the terms of the Creative Commons Attribution License (http://creativecommons.org/licenses/by/2.0), which permits unrestricted use, distribution, and reproduction in any medium, provided the original work is properly cited.

\begin{abstract}
Background: There are no published studies on stem cells from equine cord blood although commercial storage of equine cord blood for future autologous stem cell transplantations is available. Mesenchymal stem cells (MSC) have been isolated from fresh umbilical cord blood of humans collected non-invasively at the time of birth and from sheep cord blood collected invasively by a surgical intrauterine approach. Mesenchymal stem cells isolation percentage from frozenthawed human cord blood is low and the future isolation percentage of MSCs from cryopreserved equine cord blood is therefore expectedly low. The hypothesis of this study was that equine MSCs could be isolated from fresh whole equine cord blood.
\end{abstract}

Results: Cord blood was collected from 7 foals immediately after foaling. The mononuclear cell fraction was isolated by Ficoll density centrifugation and cultured in a DMEM low glucose based media at $38.5^{\circ} \mathrm{C}$ in humidified atmosphere containing $5 \% \mathrm{CO}_{2}$. In 4 out of 7 samples colonies with MSC morphology were observed. Cellular morphology varied between monolayers of elongated spindle-shaped cells to layered cell clusters of cuboidal cells with shorter cytoplasmic extensions. Positive Alizarin Red and von Kossa staining as well as significant calcium deposition and alkaline phosphatase activity confirmed osteogenesis. Histology and positive Safranin O staining of matrix glycosaminoglycans illustrated chondrogenesis. Oil Red $O$ staining of lipid droplets confirmed adipogenesis.

Conclusion: We here report, for the first time, the isolation of mesenchymal-like stem cells from fresh equine cord blood and their differentiation into osteocytes, chondrocytes and adipocytes. This novel isolation of equine cord blood MSCs and their preliminary in vitro differentiation positions the horse as the ideal pre-clinical animal model for proof-of-principle studies of cord blood derived MSCs. 


\section{Background}

In 2004, 115 thousand new Thoroughbred foals were registered worldwide [1] for whom orthopaedic injuries will be the most common cause of lost training days or premature retirement [2-5]. Traumatic osteoarthritis (OA) is estimated to constitute $60 \%$ of all equine lameness issues making it the leading cause of equine lameness [6]. Osteochondrosis (OC) lesions are other important causes of joint disease in the horse $[7,8]$.

Currently, there are no medical treatments available that can reverse cartilage injuries and most are only palliative in mild to moderate cases. Surgical cartilage and osteochondral resurfacing techniques in horses with focal OA or OC aims at either stimulated endogenous repair and or grafting of tissues [6]. Currently the surgical technique of choice for stimulated endogenous repair is abrasion arthroplasty alone or combined with subchondral bone microfracture [6]. The long-term clinical efficacy of this approach has not been reported. Grafting of equine tissues and cells for OA and OC repair remains experimental due to technical and biological problems. Retaining the transplant while maintaining articular surface congruity at the recipient site is a significant problem and the harvest of autologous graft material requires multiple surgeries or multiple surgery sites with increased risk to the patient $[6,9]$. Equine bone marrow derived autologous MSCs require time consuming in vitro propagation prior to transplantation and a decreased yield of stem cells from the bone marrow with increasing age makes the technique age-dependent which is paradoxical to the fact that many clinical cases are aged individuals [10]. Genetic modification of bone marrow derived equine MSCs might help to overcome some of these problems [11].

Mesenchymal stem cells or unrestricted somatic stem cells (USSCs) have been isolated from fresh umbilical cord blood of humans collected non-invasively at the time of birth $[12,13]$ and from sheep cord blood collected invasively by a surgical intrauterine approach [14]. Human cord blood non-hematopoietic stem cells have been differentiated into multiple cell types such as endothelial cells, neurons, smooth muscle cells, adipocytes, chondroblasts and osteoblasts [12,13,15-23]. Cartilaginous tissue has been produced in vitro from sheep cord blood [14]. Comparative studies of human bone marrow, adipose tissue and cord blood derived MSCs revealed differences in isolation frequency, proliferative capacity, in vitro differentiation potential, telomere length, and telomerase activity $[12,13,16]$. Human cord blood derived hematopoietic stem cells might even be immunologically privileged compared to bone marrow derived hematopoietic stem cells [24].
In the horse, the isolation percentage of MSCs from peripheral blood is very low and bone marrow is currently the main source of equine MSCs [25-29]. There are no peer-reviewed reports of equine adipose tissue derived stem cells although commercial marketing of so-called equine adipose tissue derived stem cell therapy is taken place today [30]. There appears to be no published studies on equine cord blood stem cells, hematopoietic or mesenchymal, although commercial storage of equine cord blood for possible future autologous stem cell transplantations is available [29]. Mesenchymal stem cells isolation from thawed human cord blood is associated with significantly reduce success $[31,32]$ and the future isolation percentage of MSCs from cryopreserved equine cord blood is therefore expectedly low.

Isolation of MSCs cells from equine umbilical cord blood could provide a non-invasive source of stem cells with potentially superior cellular characteristic to other equine stem cells with regard to immune tolerance, proliferative potential and differentiation potency. This study reports the isolation of cryopreservation and thawing tolerant MSCs from fresh equine cord blood with in vitro differentiation potential towards the osteogenic, chondrogenic and adipogenic cell lineages.

\section{Results \\ Cord blood collection}

No complications were encountered upon umbilical cord blood collection. The storage and transport temperature was $15-22^{\circ} \mathrm{C}$ (mean $\left.17.9^{\circ} \mathrm{C}\right)$, transport time was $8-24$ hours (mean 15 hours), sample volume was $65-250 \mathrm{ml}$ (mean $168 \mathrm{ml} \pm 36.08$ S.E. $\mathrm{ml}$ ), and no sample had signs of coagulation or hemolysis.

\section{Isolation and propagation}

In 4 out of 7 cord blood samples colonies with the classical MSCs morphology of adherent fibroblastoid spindleshaped cells growing in a monolayer were observed (Fig. 1a) giving an isolation percentage success rate of $4 / 7$ ( $x$ $100=57 \%$ ). The numbers of primary colonies from each sample were 1, 5, 2 and 1, respectively. Colonies were observed as early as 3 days post seeding and the first subculture was done 7 days after initial seeding. One sample containing putative MSCs colonies were subsequently discarded due to fungal contamination. Although the overall appearance of passaged cells was that of spindleshaped cells, cellular morphology did vary between very slender and elongated to more cuboidal cells with shorter cytoplasmic extensions with a layered growth (Fig. 1b). These morphological differences were seen within and between cord blood samples. Undifferentiated cells have been passaged up to 10 times and population-doubling times were calculated for a subset of cell passages. The 


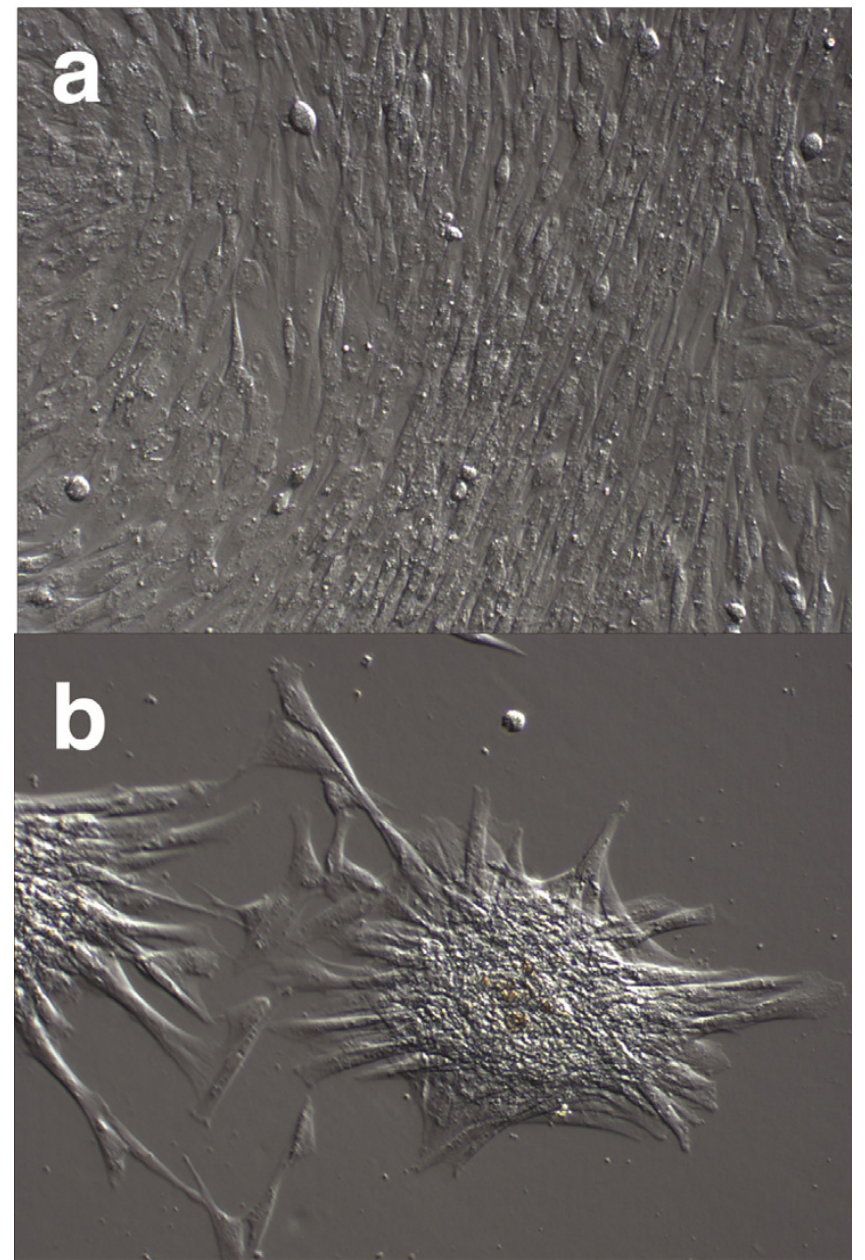

Figure I

Isolation of mesenchymal stem cells from equine umbilical cord blood. (a) Monolayer of rapidly expanding adherent spindle-shaped fibroblastoid cells compatible with undifferentiated mesenchymal stem cells $(\times 100)$. (b) Threedimensional, relief contrast image of cell cluster of rapidly expanding adherent spindle-shaped fibroblastoid cells compatible with undifferentiated mesenchymal stem cell morphology (× 100).

population doubling time varied between 0.49 and 1.22 per day with a mean of 0.77 .

In vitro differentiation results

All the depicted results in figures and pictures of the in vitro differentiation studies are from experiments performed on cryopreserved and thawed cells. Similar results were obtained from experiments performed with "fresh" undifferentiated cells which had not been previously cryopreserved.

Osteogenic induced cell cultures changed morphology from adherent monolayer of swirling spindle-shaped cells, which was still apparent in the control cultures (Fig. 2a), to layered cell clusters surrounded by a matrix-like substance positive upon Alizarin Red S (Fig. 2b) and von Kossa staining (data not shown). Statistically significant $(p<0.001)$ higher quantities of calcium deposition and alkaline phosphatase activity at the $95 \%$ confidence level were also demonstrated in these osteogenic induced culture wells (Fig. $3 \& 4$ ). The total protein content of the culture wells was significantly $(\mathrm{p}<0.001)$ lower in the osteogenic induced wells compared to the control wells indicating a lower cellularity in the induced wells (Fig. 4). Classical histological morphology of hyaline cartilage after 2 and 4 weeks of culture was evident upon staining of pellet sections with hematoxylin and eosin (Fig. 2c). Safranin O staining revealed marked deposition of glycosaminoglycans in the matrix (Fig. 2d). In comparison with control cultures in regular expansion media (Fig. 2e), marked adipogenic differentiation occurred in the presence of adipogenic induction media spiked with rabbit serum (Fig. 2f).

\section{Discussion}

Equine umbilical cord blood was collected without complications to the mare or foal at the time of foaling using a standard commercially available blood transfusion bag system. Mesenchymal stem cells with in vitro differentiation potency towards the osteogenic, chondrogenic and adipogenic cell fates were successfully isolated from the cord blood. The undifferentiated MSCs have been cryopreserved, thawed and expanded post-thawing without obvious loss of morphology, proliferative potential and differentiation capacity.

The volume of blood collected was markedly higher (mean $168 \mathrm{ml}$ ) than what has been reported in human studies (mean $42.8 \mathrm{ml}$, range 13-80 ml [12]; mean 60.9 $\mathrm{ml}$, range $17-141,5 \mathrm{ml}$ [33]). The MSCs isolation frequency of $57 \%$ is very similar to reported isolation frequencies in human studies of up to 63\% [12]. However, these high isolation frequencies are often only obtained in a subset of human cord blood samples after applying various critical parameters [12]. Correlating the number of primary colonies to the volume of blood processed might help determine whether this apparently high success rate is due to the higher volume of equine blood collected or due to higher inherent precursor frequency of these cells in equine cord blood compared to human cord blood. Here, the precursor frequency was very low with primary colonies varying between 1 and 5 per sample, indicating that this stem cell population is a very rare cell type, which is in correlation with human studies [12,13]. The different morphologies of undifferentiated cells are intriguing since they might reflect inherently different stem cell phenotypes. Morphological and differentiation potency differences between USSCs and "true" MSCs have been 


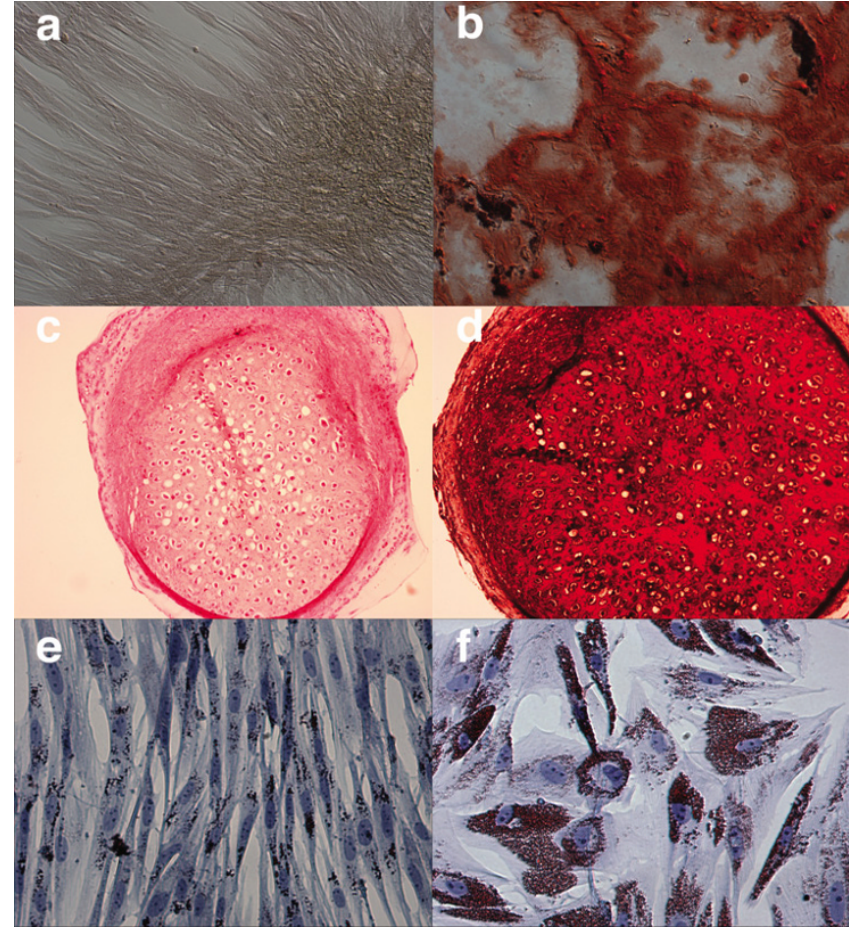

Figure 2

In vitro differentiation studies. (a) Osteogenic control after $2 \mathrm{I}$ days in regular expansion media maintained normal morphology and stain negative for Alizarin Red S (× 100). (b) Osteogenic induction after $2 \mathrm{I}$ days shows marked morphological changes and extensive extra cellular calcium deposition as demonstrated by positive Alizarin red $\mathrm{S}$ staining $(x$ 100). (c) Haematoxylin and Eosin stain of chondrogenic induced micro pellet showing classical hyaline cartilage morphology with lacunae containing chondrocytes surrounded by extra cellular matrix $(\times 100)$. (d) Safranin $O$ staining of glycosaminoglycans in the cartilage matrix (× 100). (e) Adipogenic control culture after exposure to regular expansion media shows maintenance of undifferentiated morphology and minor lipid droplet deposition $(\times 200)$. (f) Positive adipogenic induction after culture in adipogenic induction media spiked with $15 \%$ rabbit serum as demonstrated by morphological change towards larger cells with marked lipid droplet deposition stained with Oil Red O (× 200).

proposed [32]. Mesenchymal stem cells apparently form Alizarin Red positive nodules after six to eight passages and lack endodermic potential; whereas USSCs retain spindle-shaped fibroblastoid cell morphology in monolayer and have endodermic potential $[13,32]$. Whether the different morphologies noted in this study reflect USSCs and MSCs is undetermined, but warrants further investigation. So-far reduced growth rates have not been observed during sub-culturing. However, the number of samples is insufficient to draw any conclusion regarding the proliferative potential of these cells and how their proliferative potential might compare to equine bone marrow, and possibly equine adipose-derived MSCs.

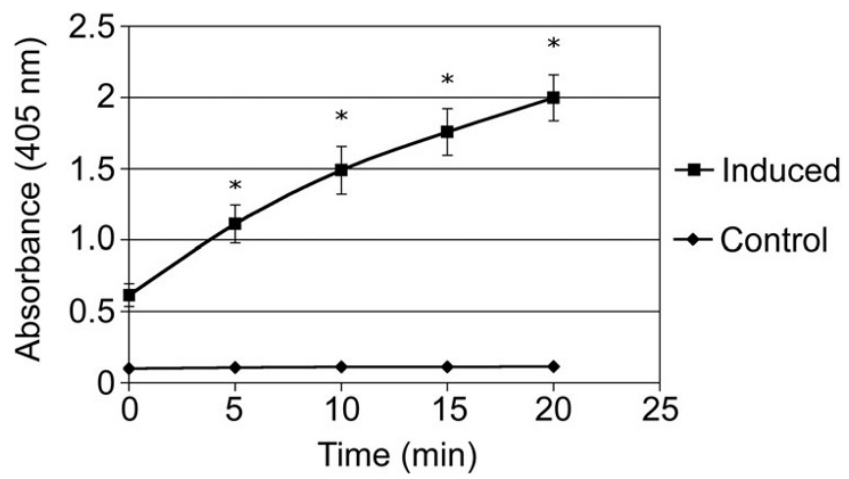

Figure 3

Alkaline phosphatase activity in control and induced osteogenic differentiation samples. Significant statistical difference $(*)$ at the $95 \%$ level between control and induced was found at $5,10,15$ and 20 minutes with p-values of < $0.00 \mathrm{I}$ at each time point. No difference was present at time 0 $(p=0.1418)$.

Although further molecular characterization is required, the osteogenic and chondrogenic potency of these cells has been convincingly demonstrated in this study. No monoclonal antibodies are presently available for immunophenotyping equine mesenchymal stem cells and a specific panel of MSC markers has not been reported in the scientific literature. If and when such an equine MSC marker panel is available, screening and cell separation of the undifferentiated umbilical cord blood derived MSCs would be very interesting in order to compare the immunophenotye profile of these cells with that of human cord blood derived MSCs and that of equine bone marrow and possibly adipose tissue derived MSCs. Nevertheless, osteogenesis has been demonstrated by both morphological and functional criteria as established in previous studies of MSCs [12,13]. Chondrogenic assessment was used using established methods and our histological findings of typical hyaline cartilage morphology with glycosaminoglycan containing matrix is in accordance with other similar studies of MSCs [13,34]. Koerner and colleagues (2006) reported that adult equine peripheral blood progenitor cells did not show any capacity to produce cartilage at the histological level [25]. This apparent difference in chondrogenic differentiation potential between equine cord blood and adult peripheral blood is undetermined but warrants further investigation. Adipogenesis of peripheral blood derived MSCs from adult horses was previously shown successfully, although reduced adipogenic potential was noted compared to human MSCs [25]. Here, rabbit serum was added to the commercial adipogenic induction media based on the work by Janderova and colleagues (2003) in which superior adipogenesis was demonstrated [35]. Adipogenic differentiation of the equine cord blood derived MSCs were only successful with the addition of rabbit serum to the 


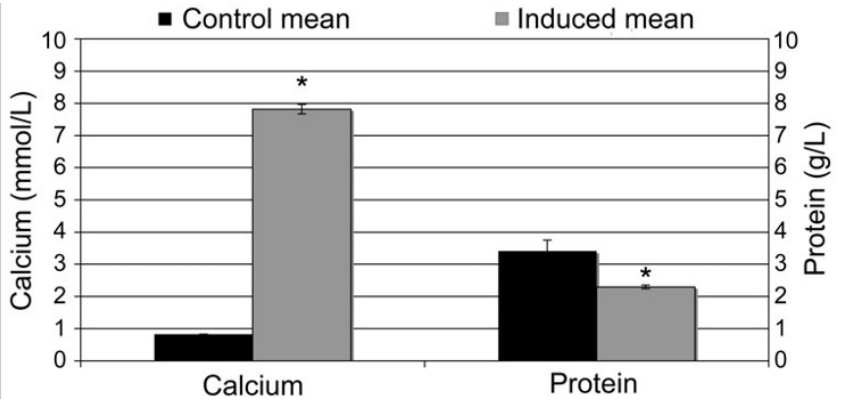

Figure 4

Mean calcium and protein levels in osteogenic differentiation studies of cord blood mesenchymal stem cells. Significant difference in calcium deposition between control and osteo-induced cultures was apparent $\left(^{*}, \mathrm{p}<\right.$ $0.00 I)$. There were significantly elevated protein levels per culture well in controls compared to osteo-induced cultures $(*, p<0.001)$.

media. Conclusions to the adipogenic potential of adult equine peripheral blood MSCs versus equine cord blood MSCs cannot be made at this point in time, since the adipogenic potential observed for both cell types was demonstrated under different culture conditions. Whether there is an inherent difference between these bloodderived blood MSCs responsible for our failure to induce adipogenesis without the addition of rabbit serum is undetermined. Also, the effect of rabbit serum on the adipogenic differentiation potential of adult equine blood MSCs is unknown. Adipogenesis was unsuccessful for human cord blood derived MSCs cultured in rabbit serum deficient media [16]. Whether this is a methodological difference or a cellular difference between equine and human cord blood MSCs warrants further studies.

Equine cord blood MSCs might have superior cellular characteristic to other equine stem cells with regard to immune tolerance, proliferative potential and differentiation potency, which are desirable traits in selection of cells for tissue engineering. Comparative studies of human bone marrow, adipose tissue and cord blood derived MSCs revealed lower isolation frequency from cord blood compared to bone marrow and adipose tissue, but cord blood derived MSCs had higher proliferative potential than both bone marrow and adipose tissue derived MSCs [16]. Longer telomeres, higher telomerase activity and superior in vitro proliferation capacity and differentiation potential of human cord blood MSCs compared to human bone marrow and adipose tissue derived MSCs have also been reported [12,13]. Human leukemia patients transfused with HLA mismatched cord blood compared to transfusions of HLA matched bone marrow showed no difference in treatment outcome [24] indicating that cord blood derived stem cells might be immunologically privileged compared to bone marrow derived stem cells. The exact immunogenic potential of umbilical cord blood derived MSCs remain undetermined. Banking of ELA matched cord blood derived stem cells would therefore be the safest approach for allogenic-based tissue engineering or stem cell-based therapies at the moment. Isolation of MSCs from cryopreserved cord blood is very difficult and MSCs isolation and expansion should be carried out from fresh cord blood prior to long-term cryopreservation $[31,32]$.

The impact of orthopaedic injuries to the health and revenue of the individual racehorse can be dramatic as was recently illustrated by the catastrophic and life-threatening injury that the 2006 Kentucky Derby champion "Barbaro" sustained during the 2006 Preakness Stakes. The financial magnitude of Thoroughbred racing in general is illustrated by the fact that in 2004 a total of 171 thousand Thoroughbred races were completed worldwide competing for a total purse value of 4 billion US dollars [1]. Bearing this in mind there is naturally a great interest in new possible treatment modalities for equine orthopaedic injuries which is also illustrated by the experimental application of autologous bone marrow MSCs and adipose tissue derived cell products to race and non-race horses with especially tendon problems [28-30]. The horse is a recognized animal model of OA induced injuries at various orthopaedic research facilities around the world for several reasons; the pathophysiology of OA appears similar between horses and humans, there are significant similarities in joint cartilage composition between horse and man and the shear size of horse joints and structures makes surgical manipulation easy compared to other domestic animal models [36]. The horse also provides a unique opportunity of studying naturally occurring injuries, which in many cases have considerable resemblance to injuries in human athletes. Deliveries of racehorses are generally observed making large-scale cord blood collection very feasible. For all of the above-mentioned similarities between horse and man, the horse now appears as a very favourable pre-clinical animal model for cord blood MSC research.

\section{Conclusion}

This novel discovery of MSCs cells in equine cord blood and our preliminary insights into the differentiation potential of these cells could have significant future impact on the equine industry and individual horse health, but could also to generate significant biological, technical and procedural knowledge spillover and potentially proof-of-principle for future therapeutic uses of human cord blood derived USSCs or MSCs.

\section{Methods \\ Cord blood collection}

Cord blood was collected, without complications to the mare or foal, from seven foals immediately after foaling. 
The collection protocol was pre-approved by the Animal Care Committee at the University of Guelph (AUP 06R076). Cord blood was collected immediately after foaling and before the umbilical cord broke spontaneously or was broken according to farm management protocol. Venipuncture of the umbilical vein was performed with a 16 G hypodermic needle attached to a $450 \mathrm{ml}$ blood transfusion collection bag (Fenwal) containing citrate phosphate dextrose adenine as the anticoagulant solution. The blood was then stored and transported at ambient temperature to the laboratory as quickly as possible.

\section{Mononuclear cell fraction isolation, seeding and MSC culture}

The mononuclear cell fraction (MNCF) was isolated by carefully loading $30 \mathrm{ml}$ of whole blood onto $10 \mathrm{ml}$ of Ficoll density media (GE Healthcare Bio-Sciences) in 50 $\mathrm{ml}$ polypropylene tubes, centrifuge for 30 minutes at room temperature at $450 \times g$ and the interphase collected after aspirating and discarding the supernatant. The interphase was washed with $20 \mathrm{ml}$ PBS and centrifuged at 150 $\times g$ for 5 minutes at room temperature. The supernatant was aspirated and the cells were washed with PBS a second time. The cells were re-suspended in the isolation media and transferred to 6-well culture dishes that had been pretreated with 100\% FBS (Invitrogen) for 30-60 minutes to prevent adherence of monocytic cells as described by Bieback et al. (2004) [12]. The isolation media was low-glucose DMEM (Cambrex Bio Science) supplemented with $30 \%$ FBS, low dexamethazone $\left(10^{-7} \mathrm{M}\right)$ (Sigma-Aldrich), penicillin (100 IU/ml) (Invitrogen), streptomycin (0.1 $\mathrm{mg} / \mathrm{ml}$ ) (Invitrogen), and ultraglutamine $(2 \mathrm{mM}$ ) (Cambrex Bio-Science) as described by Kögler et al. (2004) [13]. Incubation was at $38.5^{\circ} \mathrm{C}$ in humidified atmosphere containing $5 \% \mathrm{CO}_{2}$.

The isolation media was completely replaced after overnight incubation (12-18 hours) in order to remove nonadherent cells. Hereafter the media was completely replaced every 3 days until putative MSC colonies were noted. The cultures was inspected daily for formation of adherent spindle-shaped fibroblastoid cell colonies consistent with putative MSCs or contaminating osteo-like nodules and fungi. Initially expansion was done in 6-well culture dishes in order to allow pick-to-save procedures. Sub-culturing was performed at $60-80 \%$ confluence, when day-to-day colonic expansion was judged to slow down, or if signs of cellular detachment from the dish were noted in the center of the colony. Sub-culturing was done by chemical detachment using $0.04 \%$ trypsin/ $0.03 \%$ EDTA or by mechanically picking fibroblastoid colonies with a wiretrol pipette. Replating ratio after chemical cell detachment was 1:3. The cells in the second plate were referred to as passage 1 cells (P1). Dexamethasone was omitted from the expansion media, which was other- wise identical to the isolation media. Later, when cell numbers allowed, expansion was done in $25 \mathrm{~cm}^{2}$ or 75 $\mathrm{cm}^{2}$ tissue culture flasks. Cells were seeded at densities of $3000-25000$ cells per $\mathrm{cm}^{2}$. Cells were cryopreserved after various passages numbers.

\section{Cryopreservation and thawing of MSCs}

Cells were detached by $0.04 \%$ trypsin/0.03\% EDTA ( $1 \mathrm{ml}$ per $6-8 \mathrm{~cm}^{2}$ culture surface area), washed in expansion media at 3 times the volume of trypsin/EDTA, spun down at $150 \times g$ for 5 minutes, the supernatant was discarded and expansion media was added until the cell concentration was $1,000,000-2,000,000$ cells per $\mathrm{ml}$, then $1 \mathrm{ml}$ of cold freezing solution, (DMEM high-glucose (Invitrogen) containing 10\% FBS and 20\% DMSO (Sigma-Aldrich)) was added per $1 \mathrm{ml}$ of cell suspension and aliquots of 2 $\mathrm{ml}$ was stored overnight (12-18 hours) at $-80^{\circ} \mathrm{C}$ in a isopropanol freezing canister. The next day the vials were plunged into liquid Nitrogen for long-term storage in liquid nitrogen.

Cryovials were thawed in a $37^{\circ} \mathrm{C}$ water bath for less than 3 minutes. The cells were immediately transferred to $5 \mathrm{ml}$ of $37^{\circ} \mathrm{C}$ equilibrated expansion media and gently vortexed. The cells were centrifuged at $150 \times g$ for 5 minutes at room temperature. The cell pellet was resuspended in a minimum volume of expansion media to allow a total cell count. Further expansion media was then added pending on the desired inoculum's cell concentration and volume.

\section{In vitro differentiation studies}

Osteogenic, chondrogenic and adipogenic differentiation potential has been evaluated for one of the three propagated cell lines isolated both before and after cryopreservation.

\section{Osteogenic differentiation}

Undifferentiated cells were induced towards the osteogenic lineage using the protocol described by Jaiswal et al. (1997) [37]. Putative MSCs was seeded in six-well plates at a density of approximately 3000 cells $/ \mathrm{cm}^{2}$ and cultured in expansion media until reaching $90-100 \%$ confluence. Osteogenic differentiation was hereafter induced by culturing the cells for 20 days in osteogenic induction medium consisting of $100 \mathrm{nM}$ dexamethasone, $10 \mathrm{mM} \beta$ glycerophosphate (Sigma-Aldrich), $0.05 \mathrm{mM}$ L-ascorbic acid-2-phosphate (Fluka Biochemika), and 10\% FBS in low glucose DMEM. As a negative control an equal number of wells were maintained in expansion media for 20 days. The media in both groups were completely replaced every 4 days. Osteogenesis was evaluated by colorimetric semi-quantitative assessment of calcium deposition and alkaline phosphatase activity as well as by Alizarin Red S and von Kossa histological staining. 


\section{Semi-quantitative calcium deposition assay}

Calcium deposition was evaluated according to the protocol described by Cambrex Bio Science [38]. All culture media was aspirated from each well and the wells were washed with $1 \mathrm{ml}$ of PBS twice. After aspiration of the second PBS wash $0.5 \mathrm{ml}$ of $0.5 \mathrm{~N} \mathrm{HCl}$ was added to each well. The cells were scraped of the well and transferred to a 1.5 $\mathrm{ml}$ Eppendorf tube. An additional $0.5 \mathrm{ml}$ of $0.5 \mathrm{NHCl}$ was added to each well in order to wash of any remaining cells and this wash fluid was added to the Eppendorf tube. Eppendorf tubes with fresh samples were placed on an orbital shaker for 6 hours at $4^{\circ} \mathrm{C}$. The Eppendorf tubes were then centrifuged at $500 \times g$ for 2 minutes. The supernatant, containing the extracted calcium, was carefully aspirated without disrupting the pellet and transferred to another $1.5 \mathrm{ml}$ Eppendorf tube. A standard curve was generated following the instruction provided in the Stanbio Laboratory Calcium (CPC) Liquicolor ${ }^{\circledR}$ kit and the calcium concentration in control and osteo-induced samples were then determined. The calcium absorbance was measured at $570 \mathrm{~nm}$ by spectrometry.

\section{Semi-quantitative alkaline phosphatase enzyme activity assay}

Cell lysate supernatant was evaluated for alkaline phosphatase activity. The culture wells were rinse twice with PBS for 3 minutes. Half a millilitre of PBS was added to the well and the cells were scraped off with a tissue scraper and transferred to a $1.5 \mathrm{ml}$ Eppendorf tube. The wells were rinsed with $0.5 \mathrm{ml} \mathrm{PBS}$, which was transferred to the Eppendorf tube as well. The sample was centrifuged at $5000 \times g$ for 8 seconds. Maximum PBS was aspirated and the cell pellet was resuspended in $0.1 \mathrm{ml}$ lysis buffer (500 ml lysis buffer: $250 \mathrm{mg}$ sodium deoxycholate, $5 \mathrm{mg}$ phenylmethyl sulfonyl fluoride (PMSF), $5 \mathrm{mg}$ aprotinin, 500 $\mathrm{ml}$ nonidet P-40, $500 \mathrm{ml}$ 10\% (wt/vol) SDS) by pipetting the cells up and down several times. The tubes were left on ice for 5 minutes and vortexed for 30 seconds. The tubes were microcentrifuged at maximum speed for 10 minutes at $6^{\circ} \mathrm{C}$. Fifty microliters of the supernatant was added in duplicate from each osteo-induced and control sample to wells in a 96-well plate. The kit, p-Nitrophenyl Phosphate Liquid Substrate System (Sigma-Aldrich), was used and $50 \mu \mathrm{l}$ of p-nitrophenyl phosphate (pNPP) was added to each well. The absorbance was read at $405 \mathrm{~nm}$ on a microplate reader as soon as possible after adding the pNPP (time 0 ) and subsequent every 5 minutes for 20 minutes. The absorbance was read against $100 \mu$ l of undiluted pNPP. Covering it with aluminium foil screened the microplate from light between readings.

\section{Culture well total protein concentration}

Both calcium deposition and alkaline phosphatase activity was evaluated against the total protein content of the culture wells. Total protein concentration was determined using a DC Bio-Rad protein method. In detail, $5 \mu$ l duplicate samples of the cell lysate supernatant were added to wells of a 96-well plate. Twenty-five microlitres of working reagent $A(20 \mu \mathrm{l}$ of reagent $S$ per $1 \mathrm{ml}$ of reagent $A)$ and $200 \mu \mathrm{l}$ of reagent B were added to each sample. A standard curve was generated from bovine serum albumin samples containing 4, 2, 0.5 and $0.25 \mathrm{mg} / \mathrm{ml}$, respectively. The microplate was read at an absorbance of $630 \mathrm{~nm}$ after 15 minutes.

\section{Alizarin Red S staining}

Alizarin Red S (Sigma-Aldrich), staining calcium deposits orange red, was done by carefully aspirating the medium from each well so as not to aspirate the cells. The cells were fixed incubating in ice-cold $70 \%$ ethanol for $5 \mathrm{~min}$ utes at room temperature, before carefully aspirating the alcohol and rinsing twice (5 minutes each) with water. The water was aspirated and $1 \mathrm{ml} 2 \%$ Alizarin Red S solution was added. The plate was incubated at room temperature for 3 minutes, before removing the Alizarin Red S solution and washing the wells five times with $2 \mathrm{ml}$ water. The $\mathrm{pH}$ value of the Alizarin Red S solution was adjusted to 4.1-4.3 with ammonium hydroxide prior to the procedure.

\section{Von Kossa staining}

Von Kossa staining of calcium-phosphate deposits was performed. The cells were washed 3 times with PBS before fixation of the cells with $10 \%$ formalin for 1 hour at room temperature. The cells were washed 5 times with distilled water before adding $1 \mathrm{ml}$ of $5 \%$ silver nitrate (SigmaAldrich) and exposing to UV light for 45 minutes. The wells were washed 5 times with distilled water. Sodium thiophosphate (5\%) (Sigma-Aldrich) was added for 2 minutes and the cells were washed 3 times in distilled water. Nuclear fast red (Sigma-Aldrich) staining was done for 1 minute and the cells washed 5 times with distilled water. Calcium-phosphate deposits stained black, nuclei red and other tissues pink.

\section{Chondrogenic in vitro differentiation}

Chondrogenic differentiation was performed using a micromass culture system [39]. Briefly, undifferentiated cells $\left(2.5 \times 10^{5}\right.$ cells $)$ in a $15 \mathrm{ml}$ polypropylene tube were centrifuged at $150 \mathrm{~g}$ for $5 \mathrm{~min}$ at room temperature to form a pellet. Without disturbing the pellet, the cells were cultured for 2 and 4 weeks in $0.5 \mathrm{ml}$ complete chondrogenic differentiation medium (Cambrex Bio Science) containing $10 \mathrm{ng} / \mathrm{ml}$ TGF- $\beta 3$. Media was completely exchanged every 3 days. Pellets were fixed in 10\% formalin, imbedded in paraffin blocks and sectioned into $5 \mathrm{um}$ sections. Hematoxylin and Eosin stain (Sigma-Aldrich) as well as Safranin O (Sigma-Aldrich) staining of glycosaminoglycans confirmed chondrogenic differentiation histologically. Hematoxylin and Eosin staining of slides 
were done in a routine manner. For the Safranin O staining, sections were stained with $0.1 \%$ aqueous Safranin O for $5 \mathrm{~min}$ and the nuclei was counterstained with Weigert's iron hematoxylin (Sigma-Aldrich) according to the protocol from Cambrex Bio Science [38].

\section{Adipogenic in vitro differentiation}

Adipogenesis was induced using the protocol described by Pittenger et al. (1999) [40] and a slightly modified protocol of the one reported by Janderová et al. (2003) [35]. Six-well culture plates were seeded at $2.1 \times 10^{4}$ undifferentiated MSCs per $\mathrm{cm}^{2}$ of tissue culture surface area in $0.3 \mathrm{ml}$ of media per tissue culture surface. The cells were expanded until 100\% confluency in regular expansion media. The expansion media was completely changed every 3 days.

At confluency some wells were stained to evaluated the baseline formation of neutral lipid-vacuoles stainable with Oil Red O (Sigma-Aldrich). The used Oil Red O staining protocol was as follows; aspirate all the media off the cells, wash once with $2 \mathrm{ml}$ of PBS, replace the PBS with $2 \mathrm{ml}$ of $10 \%$ formalin for $30 \mathrm{~min}$ at room temperature to fixate the cells, replace the formalin with $2 \mathrm{ml}$ of sterile water for a few minutes, replace water with $60 \%$ isopropanol for 5 minutes, replace isopropanol with $2 \mathrm{ml}$ of Oil Red $\mathrm{O}$ working solution made up as described by Cambrex, after 5 minutes the Oil red O solution was washed of indirectly with tap water. Two ml of Harris hematoxylin (Sigma-Aldrich) was added to the well for 1 minute before being aspirated and the wells washed with warm tap water. The wells were viewed using an inverted phase contrast microscope. Lipids appeared red and nuclei appeared blue.

The remaining plates were after the cells reached 100\% confluency exposed to regular expansion media (negative control), adipogenic induction media alone, $(1 \mu \mathrm{M}$ dexamethasone, $\quad 0.5 \mathrm{mM}$ 3-isobutyl-1-methyl-xanthine (IBMX), $10 \mu \mathrm{g} / \mathrm{ml}$ recombinant human (rh) insulin, 0.2 $\mathrm{mM}$ indomethacin, and 10\% FCS in DMEM (Cambrex Bio Science)) adipogenic maintenance media alone (10 $\mu \mathrm{g} / \mathrm{ml}$ rh insulin and 10\% FCS in DMEM (Cambrex Bio Science)), cyclic exposure to adipogenic induction media for 72 hour followed by 24 hours of maintenance media, adipogenic induction media with $15 \%$ rabbit serum (Sigma-Aldrich) alone, or cyclic exposure to 72 hours of adipogenic induction media with $15 \%$ rabbit serum followed by 24 hours of maintenance media. The media was completely replaced every 3 days in wells not undergoing a cyclic protocol. Adipogenic potential was assessed by Oil Red O staining as described previously after 21 days of exposure to induction medias.

\section{Statistical analysis}

Determination of any significant statistical difference between control and induced samples in calcium deposition and alkaline phosphatase activity was performed using SAS 9.0 software. The statistical method was ANOVA (analysis of variance) for a completely randomized design with sub-sampling. There were two treatment levels (control versus induced), three replications per level (3 culture wells per treatment) and two sub-samples per replication (duplicate measurements of absorbance values). The response was the absorption readings for alkaline phosphatase, calcium and protein measures.

\section{Authors' contributions}

TGK participated in the study design, cord blood sampling, and all laboratory procedures and were the main contributor of the article draft. TH participated in cord blood sampling, most of the laboratory procedures and critiqued the final manuscript. PDT participated in the study design and critical revision of the manuscript. DHB participated in the study design, laboratory procedures, data analysis and critical revision of the manuscript.

\section{Acknowledgements}

TGK's PhD project is funded by an internationalization grant from the Danish Research Agency. Equine Guelph and the Ontario Ministry of Agriculture, Food and Rural Affairs (OMAFRA) provided additional funding. Esther Semple and Daniel Gillis are acknowledged for their respective laboratory and statistical assistance. Drs. Patrick Myers and Patrick Hearn are acknowledged for collection of blood samples.

\section{References}

I. The Jockey Club [http://www.jockeyclub.com/factbook.asp?sec tion= [7]

2. Jeffcott LB, Rossdale PD, Freestone J, Frank CJ, Towers-Clark PF: An assessment of wastage in thoroughbred racing from conception to 4 years of age. Equine Vet J 1982, I 4(3): I85- 198.

3. Bailey CJ, Reid SW, Hodgson DR, Rose RJ: Impact of injuries and disease on a cohort of two- and three-year-old thoroughbreds in training. Vet Rec 1999, I45(I7):487-493.

4. Olivier A, Nurton JP, Guthrie AJ: An epizoological study of wastage in thoroughbred racehorses in Gauteng, South Africa. J $S$ Afr Vet Assoc 1997, 68(4): I25-I29.

5. Rossdale PD, Hopes R, Digby NJ, offord K: Epidemiological study of wastage among racehorses 1982 and 1983. Vet Rec 1985, II 6(3):66-69.

6. Frisbie DD: Future directions in treatment of joint disease in horses. Vet Clin North Am Equine Pract 2005, 2 I (3):7I 3-724.

7. Stromberg B: A review of the salient features of osteochondrosis in the horse. Equine Vet I 1979, I I (4):2 | |-2 |4.

8. Jeffcott LB, Henson FM: Studies on growth cartilage in the horse and their application to aetiopathogenesis of dyschondroplasia (osteochondrosis). Vet J 1998, I56(3): I77-192.

9. Nixon AJ, Fortier LA: New horizons in articular cartilage repair. AAEP 2001:217-226.

10. Nixon AJ: Advances in cell-based grafting. ACVS 200I:I28-I3I.

II. Hidaka C, Goodrich LR, Chen CT, Warren RF, Crystal RG, Nixon A): Acceleration of cartilage repair by genetically modified chondrocytes over expressing bone morphogenetic protein7. J Orthop Res 2003, 2 I(4):573-583.

12. Bieback K, Kern S, Kluter H, Eichler H: Critical parameters for the isolation of mesenchymal stem cells from umbilical cord blood. Stem Cells 2004, 22(4):625-634.

13. Kogler G, Sensken S, Airey JA, Trapp T, Muschen M, Feldhahn N, Liedtke S, Sorg RV, Fischer J, Rosenbaum C, et al.: A new human 
somatic stem cell from placental cord blood with intrinsic pluripotent differentiation potential. J Exp Med 2004, 200(2): $123-135$

14. Fuchs JR, Hannouche D, Terada S, Zand S, Vacanti JP, Fauza DO: Cartilage engineering from ovine umbilical cord blood mesenchymal progenitor cells. Stem Cells 2005, 23(7):958-964.

15. Watt SM, Contreras M: Stem cell medicine: umbilical cord blood and its stem cell potential. Semin Fetal Neonatal Med 2005, I 0(3):209-220.

16. Kern S, Eichler H, Stoeve J, Kluter H, Bieback K: Comparative analysis of mesenchymal stem cells from bone marrow, umbilical cord blood or adipose tissue. Stem Cells 2006, 24(5): I294-| 30I

17. Goessler UR, Bieback K, Bugert P, Heller T, Sadick H, Hormann K, Riedel $F$ : In vitro analysis of integrin expression during chondrogenic differentiation of mesenchymal stem cells and chondrocytes upon dedifferentiation in cell culture. Int J Mol Med 2006, I7(2):30I-307.

18. Goessler UR, Bugert P, Bieback K, Bag S, Sadick H, Kluter H, Hormann K, Riedel F: A comparison of the gene expression patterns of human chondrocytes and chondrogen differentiated mesenchymal stem cells for tissue engineering. Hno 2005, 54(4):258-266.

19. Goessler UR, Bugert P, Bieback K, Deml M, Sadick H, Hormann K, Riedel F: In-vitro analysis of the expression of TGFbeta superfamily-members during chondrogenic differentiation of mesenchymal stem cells and chondrocytes during dedifferentiation in cell culture. Cell Mol Biol Lett 2005, I 0(2):345-362.

20. Feldmann RE Jr, Bieback K, Maurer MH, Kalenka A, Burgers HF, Gross B, Hunzinger C, Kluter H, Kuschinsky W, Eichler H: Stem cell proteomes: a profile of human mesenchymal stem cells derived from umbilical cord blood. Electrophoresis 2005 , 26(I4):2749-2758.

21. Aoki M, Yasutake M, Murohara T: Derivation of functional endothelial progenitor cells from human umbilical cord blood mononuclear cells isolated by a novel cell filtration device. Stem Cells 2004, 22(6):994-1002.

22. Jager M, Sager M, Knipper A, Degistirici O, Fischer J, Kogler G, Wernet $P$, Krauspe $R$ : In vivo and in vitro bone regeneration from cord blood derived mesenchymal stem cells. Orthopade 2004 33(I2): |36|-|372.

23. Le Ricousse-Roussanne S, Barateau V, Contreres JO, Boval B, KrausBerthier L, Tobelem G: Ex vivo differentiated endothelial and smooth muscle cells from human cord blood progenitors home to the angiogenic tumor vasculature. Cardiovasc Res 2004, 62(I):176-184.

24. Rocha V, Labopin M, Sanz G, Arcese W, Schwerdtfeger R, Bosi A, Jacobsen N, Ruutu T, de Lima M, Finke J, et al.: Transplants of umbilical-cord blood or bone marrow from unrelated donors in adults with acute leukemia. The New England journal of medicine 2004, 35 I (22):2276-2285.

25. Koerner J, Nesic D, Romero JD, Brehm W, Mainil-Varlet P, Grogan $S P$ : Equine peripheral blood-derived progenitors in comparison to bone marrow-derived mesenchymal stem cells. Stem Cells 2006, 24(6): $1613-1619$.

26. Fortier LA, Nixon AJ, Williams J, Cable CS: Isolation and chondrocytic differentiation of equine bone marrow-derived mesenchymal stem cells. Am J Vet Res 1998, 59(9): I I82-I I87.

27. Fortier LA: Stem cells: classifications, controversies, and clinical applications. Vet Surg 2005, 34(5):4I5-423.

28. Smith RK, Korda M, Blunn GW, Goodship AE: Isolation and implantation of autologous equine mesenchymal stem cells from bone marrow into the superficial digital flexor tendon as a potential novel treatment. Equine Vet J 2003, 35(I):99-102.

29. VetCell [http://www.vetcell.com]

30. Vet-Stem [http://www.vet-stem.com]

31. Kogler G, Radke TF, Lefort A, Sensken S, Fischer J, Sorg RV, Wernet $P$ : Cytokine production and hematopoiesis supporting activity of cord blood-derived unrestricted somatic stem cells. Exp Hematol 2005, 33(5):573-583.

32. Kogler G, Sensken S, Wernet P: Comparative generation and characterization of pluripotent unrestricted somatic stem cells with mesenchymal stem cells from human cord blood. Exp Hematol 2006, 34(I I): I589-I595.

33. Belvedere $O$, Feruglio $C$, Malangone W, Bonora ML, Minisini AM, Spizzo R, Donini A, Sala P, De Anna D, Hilbert DM, et al.: Increased blood volume and CD34(+)CD38(-) progenitor cell recovery using a novel umbilical cord blood collection system. Stem Cells 2000, 18(4):245-25I.

34. Mackay AM, Beck SC, Murphy JM, Barry FP, Chichester CO, Pittenger MF: Chondrogenic differentiation of cultured human mesenchymal stem cells from marrow. Tissue engineering 1998, 4(4):415-428.

35. Janderova L, McNeil M, Murrell AN, Mynatt RL, Smith SR: Human mesenchymal stem cells as an in vitro model for human adipogenesis. Obesity research 2003, I I(I):65-74.

36. Frisbie DD, Cross MW, Mcllwraith CW: A comparative study of articular cartilage thickness in the stifle of animal species used in human pre-clinical studies compared to articular cartilage thickness in the human knee. Vet Comp Orthop Traumatol 2006, 19(3): 142-146.

37. Jaiswal N, Haynesworth SE, Caplan Al, Bruder SP: Osteogenic differentiation of purified, culture-expanded human mesenchymal stem cells in vitro. J Cell Biochem 1997, 64(2):295-3I2.

38. Cambrex Bio Sciences [http://www.lonzabioscience.com/Con tent/Documents/Bioscience/Cal cium\%20Deposition\%20Assay\%2\%20WEB-PR-PT-250I.pdf

39. Johnstone B, Hering TM, Caplan Al, Goldberg VM, Yoo JU: In vitro chondrogenesis of bone marrow-derived mesenchymal progenitor cells. Exp Cell Res 1998, 238(I):265-272.

40. Pittenger MF, Mackay AM, Beck SC, Jaiswal RK, Douglas R, Mosca JD, Moorman MA, Simonetti DW, Craig S, Marshak DR: Multilineage potential of adult human mesenchymal stem cells. Science 1999, 284(54 I I):|43-| 47.
Publish with BioMed Central and every scientist can read your work free of charge

"BioMed Central will be the most significant development for disseminating the results of biomedical research in our lifetime. "

Sir Paul Nurse, Cancer Research UK

Your research papers will be:

- available free of charge to the entire biomedical community

- peer reviewed and published immediately upon acceptance

- cited in PubMed and archived on PubMed Central

- yours - you keep the copyright
BioMedcentral 